\title{
KAJIAN KUALITAS AIR DANAU MANINJAU DAN DANAU RAWAPENING MELALUI PENDEKATAN INDEKS KUALITAS AIR
}

\author{
WATER QUALITY STUDY OF \\ MANINJAU AND RAWAPENING LAKES THROUGH \\ THE WATER QUALITY INDEX APPROACH
}

\author{
Ernawita Nazir, Anwar Hadi, Arum Prajanti, Eva Lindasari Nasution 1)
}

(Diterima tanggal 2 Maret 2017Disetujui tanggal 4 Mei 2017)

\begin{abstract}
ABSTRAK
Dalam rangka menjaga dan melestarikan kualitas air danau, maka perlu dilakukan pemantauan secara terencana dan terus - menerus. Namun, pemantauan berbagai parameter kualitas air danau yang dilakukan belum menggambarkan status kualitas air danau yang dapat dipahami secara sederhana. Oleh sebab itu diperlukan suatu pendekatan yang dapat mengambarkan kualitas air danau secara keseluruhan pada suatu waktu dan lokasi, berdasarkan pada beberapa parameter kualitas air. Tujuannya untuk merubah data pengujian menjadi informasi, yang diungkapkan dalam satu nilai tunggal. Kajian kualitas air danau melalui pendekatan indeks kualitas air dilakukan di danau Maninjau dan danau Rawapening dengan batasan ruang lingkup kajian meliputi: pH, DO, TSS, COD, TP, TN, Sulfida dan klorophil-a. Metode yang digunakan adalah metode yang dikembangkan oleh National Sanitation Foundation's Water Quality Indeks. Hasil uji coba perhitungan indeks kualitas air danau Maninjau dan Danau Rawapening terhadap nilai Kelas II dalam PP 82 terhadap 8 parameter tersebut, diperoleh indeks 89,34 dan dan 79,72 dengan kategori baik.
\end{abstract}

Kata kunci: indeks kualitas air danau, pemantauan

\begin{abstract}
In order to maintain and conserve the lake water quality, it is necessary to conduct a planned and continuously monitoring. However, the monitoring of various parameters of lake water quality, do not describe the status of the water quality of the lake which can be understood simply. Results of water quality monitoring would be more meaningful if it is able to illustrate the status of water quality as an index which is expressed in a single value. Water quality index approach were applied in the study of the lake waterquality on the Maninjau and Rawapening lakes with the limitation scope of parameters, as follows: $p H, D O$, TSS, COD, TP, TN, Sulfide and chlorophil-a. The method used is a method developed by the National Sanitation Foundation's Water Quality Index. Based on the water quality index calculation for 8 parameters, resulted 89.34 the index value for the Maninjau lake was and 79.72 index value for the Rawapening lake. If compared with the index value obtained from the calculation using the value of water quality criteria class II according the Indonesian Government Regulation No. 82 Year 2001, the both results showed the same category of lake water quality that was good.
\end{abstract}

Keywords: lake, water quality index, monitoring

${ }^{1}$ Pusat Penelitian dan Pengembangan Kualitas dan Laboratorium Lingkungan - Badan Penelitian, Pengembangan dan Inovasi, Kementerian Lingkungan Hidup dan Kehutanan, Kawasan PUSPIPTEK Gedung $210 \mathrm{Jl}$. Raya PUSPIPTEK Serpong - Tangerang Banten, Telp/Faks. 021-7560981, email: witanazir@yahoo.co.id 


\section{PENDAHULUAN}

Danau merupakan wadah air dan ekosistem yang terbentuk secara alamiah dan berfungsi sebagai tempat berlangsungnya siklus hidup flora dan fauna serta sumber air yang dapat digunakan langsung oleh masyarakat sekitarnya. Dalam rangka menjaga dan melestarikan keberadaan air danau, maka perlu dilakukan pemantauan kualitas air danau secara terencana dan terus - menerus. Pemantauan secara kontinyu terhadap paramater parameter kualitas air tersebut, berakibat pada akumulasi informasi/data yang umumnya tidak dapat memberikan keputusan langsung terhadap kualitas air, karena bisa saja salah satu parameter memenuhi kriteria mutu air tetapi parameter yang lain tidak ${ }^{(24)}$. Sehubungan dengan hal tersebut, berbagai metode pengolahan data telah digunakan, agar data dapat ditampilkan menjadi informasi yang lebih komunikatif dan mudah digunakan.

Para ilmuwan telah mengembangkan beberapa metode transformasi data dari hasil analisis parameter kualitas air menjadi suatu nilai tunggal, yang dikenal dengan nama indeks kualitas air (Water Quality Index, WQI ${ }^{[1]}$, yaitu suatu metode yang menyatakan kualitas air dengan cara yamg sederhana yang dapat merespon perubahan karakteristik dasar dari air dan merubah data parameter kualitas air yang kompleks menjadi informasi yang mudah dipahami (Brown et al tahun 1970 dalam Vivi , 2011).

Kajian kualitas air danau melalui pendekatan indeks kualitas air dilakukan di danau Maninjau Sumatera Barat dan danau Rawapening Jawa Tengah.
Parameter kualitas air danau yang digunakan sebagai batasan ruang lingkup kajian meliputi: pH, DO, TSS, COD, TP, TN, Sulfida dan klorofil-a. Adapun tujuan dari kajian ini adalah untuk memperoleh rumusan indeks kualitas air danau yang dapat digunakan untuk menggambarkan kualitas air danau secara umum $^{[3-5]}$. Indeks kualiats air danau yang ditetapkan dapat digunakan bagi para pengambil keputusan baik di tingkat pusat maupun di daerah untuk melakukan pengelolaan air danau dengan baik dan benar $^{[6-10]}$.

\section{METODOLOGI}

Metode yang digunakan untuk membuat rumusan perhitungan indeks kualitas air danau (WQI) adalah metode yang dikembangkan oleh National Sanitation Foundation Water Quality Index. Tujuan utama penggunaan WQI adalah untuk merubah data parameter kualitas air yang kompleks menjadi informasi yang mudah dipahami dan digunakan. Metode ini dipilih, karena merupakan salah satu metode yang paling efektif untuk mengukur kualitas air, telah banyak digunakan diberbagai negara maju (11) dan penentuannya lebih mudah dilakukan, yaitu cukup dengan menjumlahkan perkalian sub indeks masing masing parameter dengan bobot tiap parameter. Parameter yang diukur mewakili parameter fisik, kimia dan biologi ${ }^{(25)}$.

Rumusan Indeks Kualitas Air (WQI) yang ditetapkan diverifikasi dengan data primer hasil pengujian kualitas air dari Danau Maninjau dan Danau Rawapening. Pengujian sampel dilakukan di laboratorium, kecuali beberapa parameter seperti $\mathrm{pH}$ dan DO yang dilakukan langsung di lapangan. Metode yang 
digunakan untuk pengujian disajikan pada Tabel 1 berikut;

Tabel 1: Metode dan peralatan yang digunakan untuk pengujian air danau

\begin{tabular}{|c|l|c|l|c|}
\hline No & Parameter & Satuan & \multicolumn{1}{|c|}{ Peralatan } & Metode Up \\
\hline 1 & TSS & $\mathrm{mg} / \mathrm{L}$ & Timbangan analitik & SNI 06-6989.3-2004 \\
\hline 2 & $\mathrm{pH}$ & $\mathrm{mg} / \mathrm{L}$ & $\mathrm{pH}$ meter & SNI 06- 6989.11-2004 \\
\hline 3 & DO & $\mathrm{mg} / \mathrm{L}$ & alat titrasi & JIS K 0102 -32.1-2008 \\
\hline 4 & Total Nitrogen & $\mathrm{mg} / \mathrm{L}$ & spektrofotometer & JIS K 0102-45.2-2008 \\
\hline 5 & Total Phospor & $\mathrm{mg} / \mathrm{L}$ & spektrofotometer & JIS K 0102-46.3.1-2008 \\
\hline 6 & COD & $\mathrm{mg} / \mathrm{L}$ & spektrofotometer & SNI 06-6989.2-2009 \\
\hline 7 & Sulfida & $\mathrm{mg} / \mathrm{L}$ & spektrofotometer & SNI 06-6989.70-2009 \\
\hline 8 & Klorofil a & $\mathrm{mg} / \mathrm{m}^{3}$ & spektrofotometer & APHA 10200H-2012 \\
\hline
\end{tabular}

Para ilmuwan, pemerhati, praktisi dan pakar dibidang kualitas air danau diminta menentukan parameter prioritas yang dapat dipertimbangkan dalam indeks kualitas air danau. Sehubungan dengan hal tersebut, kuesioner disusun sedemikian rupa sehingga dapat digunakan untuk mengetahui prioritas parameter kualitas air danau. Parameter yang telah dipilih diberi nilai pembobotan dengan skala 1 - 5, yang bermakna bahwa keberadaan parameter kualitas air danau, adalah:

- skala 1 : sangat penting sekali;

- skala 2 : sangat penting;

- skala 3 : penting;

- skala 4 : kurang penting; dan

- skala 5 : tidak penting

Setelah itu, para ilmuwan, pemerhati, praktisi dan pakar diminta memberikan persepsinya terhadap kadar suatu parameter air danau yang diungkapkan dalam suatu indek kualiatas air dengan skala 0 - 100 . Skala 0 merupakan indeks terburuk dan indeks terbaik memiliki skala 100 . Hubungan antara sub-indeks dan kadar dari suatu parameter kualitas air danau diplotkan menjadi kurva serta ditentukan model persamaan matematikanya untuk masing-masing parameter kualitas air prioritas $^{[18-20]}$. Penentuan indeks kualitas air danau keseluruhan dilakukan setelah melakukan penggabungan nilai sub-indeks tiap parameter dan mengalikannya dengan bobot dari masing-masing parameter.

\section{Lokasi Sampling}

Pengambilan contoh uji air Danau Rawapening dilakukan pada bulan Maret 2016 di lima lokasi pengambilan contoh uji. Danau Rawapening terdapat di Kabupaten Semarang, Jawa Tengah dengan luas mencapai luas $2.670 \mathrm{Ha}$. Secara fisik hampir $70 \%$ permukaan air danau Rawapening ditutupi oleh tumbuhan air, enceng gondok sebagaimana Gambar 1.

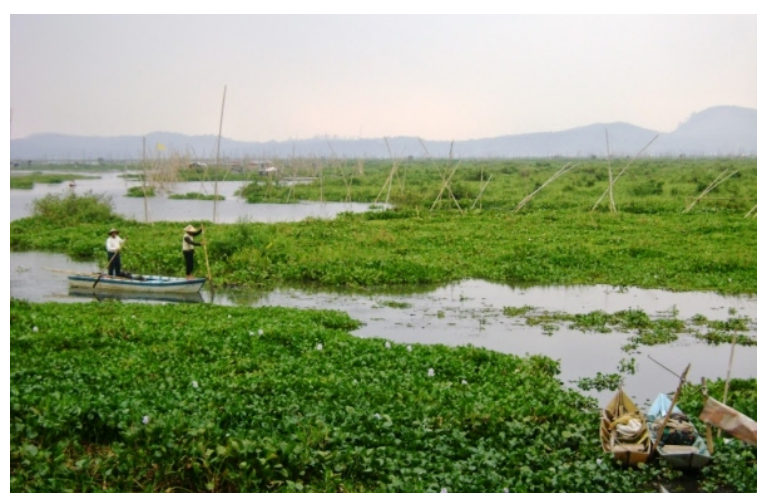

Gambar 1: Eceng gondok di Danau Rawapening

Danau Rawapening merupakan reservoir alami dan landmark Jawa Tengah (Bappeda Prov Jateng, 2005), merupakan danau paling kecil diantara 15 danau prioritas nasional 2010 - 2014 dengan luas $2.670 \mathrm{Ha}$ (KLH, 2010), namun memiliki fungsi sangat penting untuk PLTA, pengendali banjir, sumber air baku air minum, irigasi, perikanan dan pariwisata ${ }^{(2)}$. Lokasi pengambilan contoh uji di Danau Rawapening yakni outlet, 
pertemuan Sungai Toroh dan Sungai Goleh, tengah danau (Tempuran, antara KTA dan pengerukan) serta sumber mata air, sebagai berikut:

1. Pertemuan S. Toroh dan S. Galeh S: $07^{\circ} 16^{\prime} 77,3^{\prime \prime} \mathrm{E}: 110^{\circ} 25^{\prime} 79.5^{\prime \prime}$;

2. Tengah Danau, S: $00^{\circ} 16^{\prime} 55,2^{\prime \prime}, \mathrm{E}: 100^{\circ} 13^{\prime}$ 07.0”;

3. Keramba Jaring Apung (KJA), S: $07^{\circ} 18^{\prime} 35,8^{\prime \prime}, \mathrm{E}: 110^{\circ} 25^{\prime} 49.2^{\prime \prime}$;

4. Mata Air, S: $07^{\circ} 17^{\prime} 40,3^{\prime \prime}, \mathrm{E}: 110^{\circ} 25^{\prime} 49.2^{\prime \prime}$;

5. Outlet Jembatan Tuntang, S: $07^{\circ} 16^{\prime} 11,0^{\prime \prime}, \mathrm{E}: 110^{\circ} 26^{\prime} 20.9^{\prime \prime}$.
Danau Maninjau terletak $38 \mathrm{~km}$ sebelah barat dari pusat kota Bukit Tinggi, tepatnya di Kecamatan Tanjung Raya, Kabupaten Agam. Danau ini merupakan bekas kawah sehingga dikategorikan sebagai danau bekas kawah. Bagian luar dinding bekas kawah saat ini merupakan daerah perbukitan dengan kemiringan antara $15 \%$ sampai $100 \%$ Luas danau diperkirakan $\pm 9.950 \mathrm{Ha}$ dengan luas daerah tangkapan danau mencapai $24.800 \mathrm{Ha}$ (2). Lokasi pengambilan contoh uji air danau Maninjau (Gambar 3), sebagai berikut:

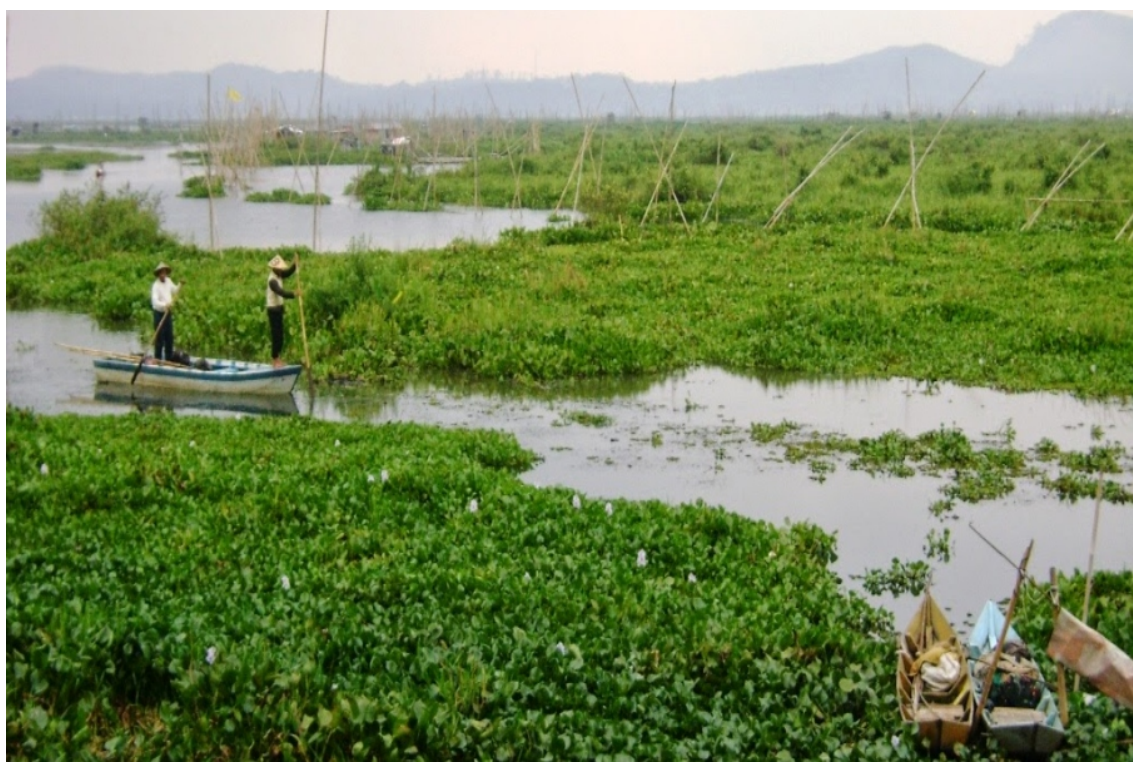

Gambar 2: Lokasi sampling air Danau Rawapening

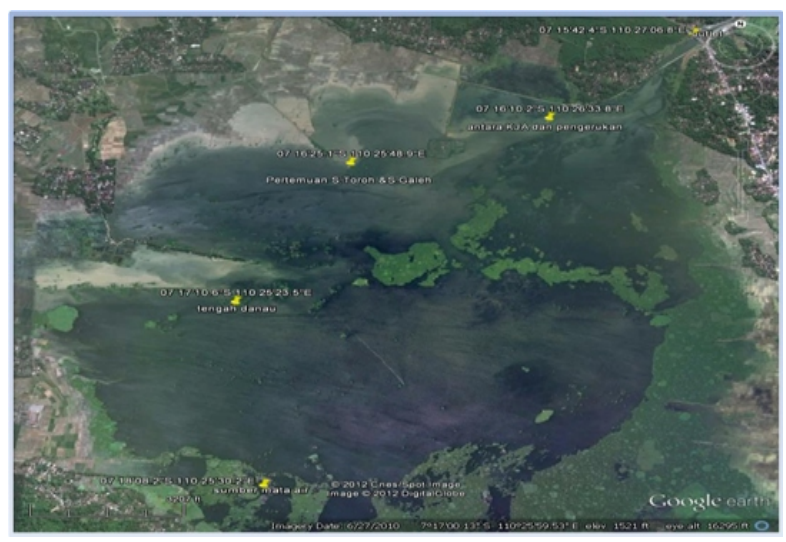

Gambar 2: Lokasi sampling air Danau Rawapening

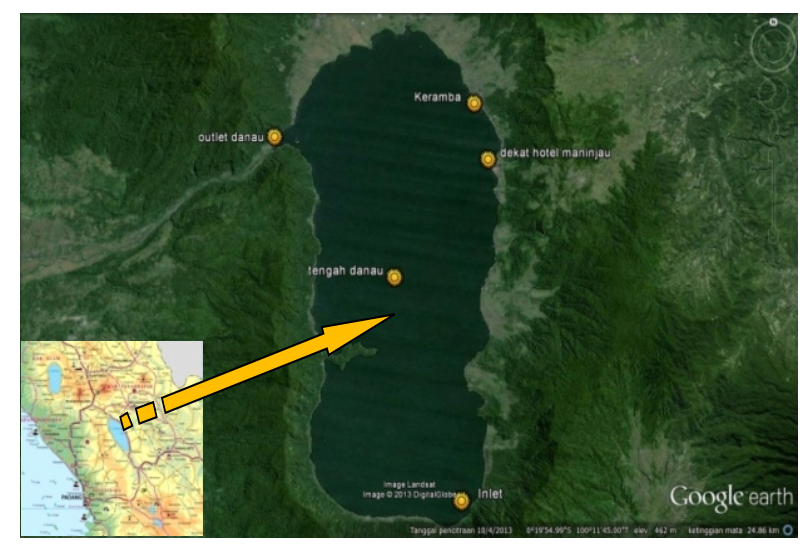

Gambar 3 : Lokasi sampling air Danau Maninjau 


\section{HASIL PEMBAHASAN}

Delapan parameter yang dipilih untuk perhitungan indeks kualitas air danau yaitu pH, DO, TSS, COD, TP, TN, Sulfida dan klorofil a, karena merupakan parameter dalam kriteria mutu air sesuai Peraturan Pemerintah Republik Indonesia Nomor 82 tahun 2001 (PP No. 82/2001) tentang Pengelolaan Kualitas Air dan Pengendalian Pencemaran Air. Parameter tersebut dapat mewakili pencemar dari berbagai kegiatan di sekitar danau. Selain itu, metode pengujian parameter tersebut relatif mudah sehingga dapat dilakukan oleh laboratorium daerah. Pertimbangan pemilihan 8 parameter tersebut dan skala pembobotan dijelaskan sebagaimana Tabel 2.

Tabel 2: Hasil Pembobotan parameter kualitas air danau

\begin{tabular}{|l|l|l|}
\hline No & \multicolumn{1}{|c|}{ Parameter } & Bobot \\
\hline 1. & pH & 0.14 \\
\hline 2. & TSS & 0.11 \\
\hline 3. & DO & 0.14 \\
\hline 4. & COD & 0.11 \\
\hline 5. & T-Pospat & 0.13 \\
\hline 6. & T-Nitrogen & 0.13 \\
\hline 7. & Sulfida & 0.13 \\
\hline 8. & Klorofil a & 0.11 \\
\hline
\end{tabular}

Indeks kualitas air danau dapat dihitung bila kadar parameter kualitas air danau dimasukkan ke dalam persamaan matematika dan dikalikan dengan faktor pembobot untuk masing-masing parameter terkait. Total indeks kualitas air danau yang diperoleh diklasifikasikan berdasarkan rentang sesuai National Sanitation Foundation - Water Quality Index (NSF - WQI), sebagai berikut:

$$
\begin{aligned}
& \text { 1. } 0-25=\text { sangat jelek } \\
& \text { 2. } 26-50=\text { jelek } \\
& \text { 3. } 51-70=\text { sedang } \\
& \text { 4. } 71-90=\text { baik } \\
& \text { 5. } 91-100=\text { sangat baik }
\end{aligned}
$$

Untuk menghitung NSF - WQI digunakan persamaan berikut:

$$
W Q I=\sum_{i=0}^{n} W_{i} x q_{i}
$$

keterangan:

$\mathrm{q}_{\mathrm{i}}$ : nilai $\mathrm{q}$ awal yang diberikan untuk masing-masing parameter.

Nilai q ditentukan dengan grafik sub-indeks masing - masing parameter.

$\mathrm{W}_{\mathrm{i}}$ : bobot masing - masing parameter dengan nilai yaitu:

$$
\begin{array}{ll}
\mathrm{W}_{\mathrm{i}}-\mathrm{DO} & =0,14 ; \\
\mathrm{W}_{\mathrm{i}}-\mathrm{pH} & =0,14 ; \\
\mathrm{W}_{\mathrm{i}}-\mathrm{TSS} & =0,11 ; \\
\mathrm{W}_{\mathrm{i}}-\mathrm{COD} & =0,11 ; \\
\mathrm{W}_{\mathrm{i}}-\mathrm{TP} & =0,13 ; \\
\mathrm{W}_{\mathrm{i}}-\mathrm{TN} & =0,13 ; \\
\mathrm{W}_{\mathrm{i}} \text {-sulfida } & =0,13 ; \text { dan } \\
\mathrm{W}_{\mathrm{i}}-\text { Klorophil-a } & =0,11 .
\end{array}
$$

Berdasarkan hasil kuesioner para pakar diperoleh kurva hubungan antara kadar masing-masing parameter dengan nilai sub-indek kualitas air danau seperti Gambar 4. Kurva nilai sub-indek kualitas masingmasing parameter yang terbentuk dapat digunakan sebagai acuan untuk mendapatkan nilai sub-indek kualitas air berdasarkan hasil pengujian di laboratorium ${ }^{[21-23]}$. 

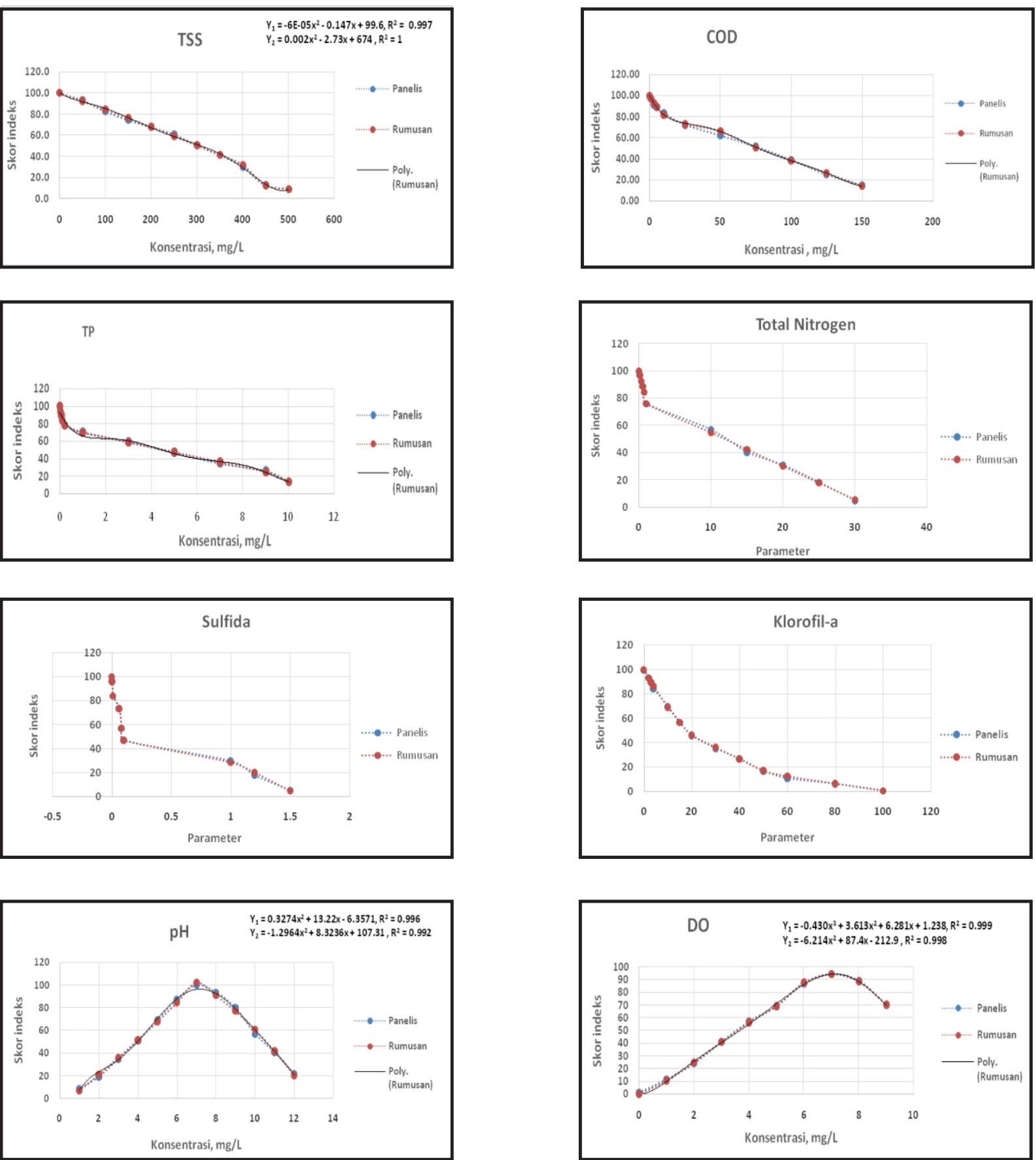

Gambar 4: Kurva Sub-indeks kualitas air danau

Kurva sub-indek kualitas air danau masing - masing parameter diungkapkan dalam persamaan matematika, sebagaimana dituangkan dalam Tabel 3. Kriteria batas keberterimaan persamaan matematika yang diperoleh adalah koefisien determinasi kurang dari sama dengan 0,990. Jika koefisien determinasi yang diperoleh kurang dari 0,990, maka gunakan persamaan matematika lainnya hingga diperoleh koefisien determinasi lebih dari 0,990. Kemudian rumusan matematika yang diperoleh, diuji coba menggunakan data hasil pengujian air danau Maninjau dan Rawapening. 
Tabel 3: Persamaan matematika kurva nilai sub-indek kualitas air danau

\begin{tabular}{|c|c|c|c|}
\hline \multirow[b]{2}{*}{ No } & \multirow[b]{2}{*}{ Parameter } & \multicolumn{2}{|c|}{ Persamaan matematika kurva nilai sub-indek kualitas air } \\
\hline & & Persamaan matematika & $\begin{array}{c}\text { Koef. } \\
\text { determinasi }\end{array}$ \\
\hline \multirow{2}{*}{1} & & $\mathrm{Y}_{1}=0.3274 \mathrm{x}^{2}+13.22 \mathrm{x}-6.3571$ & $\mathrm{R}^{2}=0.996$ \\
\hline & $\mathrm{pH}$ & $Y_{2}=-1.2964 x^{2}+8.3236 x+107.31$ & $\mathrm{R}^{2}=0.992$ \\
\hline \multirow{2}{*}{2} & & $Y_{1}=-0.430 x^{3}+3.613 x^{2}+6.281 x+1.238$ & $\mathrm{R}^{2}=0.999$ \\
\hline & DU & $Y_{2}=-6.214 x^{2}+87.4 x-212.9$ & $\mathrm{R}^{2}=0.998$ \\
\hline \multirow{2}{*}{3} & TSS & $Y_{1}=-6 E-05 x^{2}-0.147 x+99.6$ & $\mathrm{R}^{2}=0.997$ \\
\hline & IDS & $Y_{2}=0.002 x^{2}-2.73 x+674$ & $\mathrm{R}^{2}=1$ \\
\hline \multirow{5}{*}{4} & COD & $Y_{1}=-0.0008 x^{3}+0.058 x^{2}-2.130 x+98.56$ & $\mathrm{R}^{2}=0.996$ \\
\hline & CUD & $Y_{2}=-0.482 x+86.7$ & $\mathrm{R}^{2}=0.997$ \\
\hline & & $\mathrm{Y}_{1}=0.974 \mathrm{x}+0.02$ & $\mathrm{R}^{2}=1$ \\
\hline & & $Y_{2}=2583 x^{2}-311.6 x+99$ & $\mathrm{R}^{2}=1$ \\
\hline & & $\mathrm{Y}_{3}=0.930 \mathrm{x}+0.044$ & $\mathrm{R}^{2}=1$ \\
\hline \multirow[t]{6}{*}{5} & Total phospor & $Y_{4}=0.0932 x+0.106$ & $\mathrm{R}^{2}=1$ \\
\hline & & $Y_{5}=-9.875 x+79.875$ & $\mathrm{R}^{2}=1$ \\
\hline & & $Y_{6}=-5.64 x+75.56$ & $\mathrm{R}^{2}=1$ \\
\hline & & $Y_{7}=-12.3 x+136.7$ & $\mathrm{R}^{2}=1$ \\
\hline & & $Y_{1}=-29 x+100$ & $\mathrm{R}^{2}=1$ \\
\hline & & $Y_{2}=-23 x+99.4$ & $\mathrm{R}^{2}=1$ \\
\hline \multirow{6}{*}{6} & Total & $Y_{3}=-18.5 x+98.05$ & $\mathrm{R}^{2}=1$ \\
\hline & Nitrogen & $Y_{4}=-21.5 x+104.1$ & $\mathrm{R}^{2}=1$ \\
\hline & & $Y_{5}=-28 x+104.1$ & $\mathrm{R}^{2}=1$ \\
\hline & & $Y_{6}=-2.4573 x+79.382$ & $\mathrm{R}^{2}=1$ \\
\hline & & $Y_{1}=-4000 x+100$ & $\mathrm{R}^{2}=1$ \\
\hline & & $Y_{2}=-1333.3 x+97.333$ & $\mathrm{R}^{2}=1$ \\
\hline \multirow{5}{*}{7} & Sulfide & $Y_{3}=-210 x+86.1$ & $\mathrm{R}^{2}=1$ \\
\hline & suimida & $Y_{4}=-825 x+123$ & $\mathrm{R}^{2}=1$ \\
\hline & & $Y_{5}=-500 x+97$ & $\mathrm{R}^{2}=1$ \\
\hline & & $Y_{6}=-18.913 x^{2}+0 . .0671 x+47.284$ & $\mathrm{R}^{2}=0.998$ \\
\hline & & $Y_{1}=0.0418 x^{2}-3.517 x+100$ & $\mathrm{R}^{2}=0.994$ \\
\hline \multirow[t]{2}{*}{8} & Klorophil - a & $Y_{2}=-0.955 x+64.8$ & $\mathrm{R}^{2}=1$ \\
\hline & & $Y_{3}=-0.3014 x+30.698$ & $\mathrm{R}^{2}=1$ \\
\hline
\end{tabular}

Tabel 4 adalah contoh perhitungan indeks kualitas air danau Maninjau di lokasi inlet berdasar kan data hasil pengujian, mengacu kriteria mutu air (KMA) kelas II PP No.82/2001 mengguna kan WQI calculator. Berdasarkan simulasi, diperoleh nilai indeks kualitas air Danau Maninjau seperti berikut:

Tabel 4: Perhitungan indeks kualitas air danau Maninjau di lokasi inlet

\begin{tabular}{|c|c|c|c|c|c|}
\hline Parameter & $\begin{array}{c}\text { Hasil } \\
\text { Pengujian }\end{array}$ & Satuan & $\begin{array}{c}\text { Nilai } \\
\text { Sub-indek }\end{array}$ & $\begin{array}{c}\text { Faktor } \\
\text { Pembobot }\end{array}$ & $\begin{array}{c}\text { Sub } \\
\text { Total }\end{array}$ \\
\hline pH & 8.4 & --- & 85.75 & 0.14 & 11.99 \\
TSS & 2.4 & $\mathrm{mg} / \mathrm{L}$ & 99.64 & 0.11 & 11.07 \\
DO & 7.6 & $\mathrm{mg} / \mathrm{L}$ & 92.33 & 0.14 & 13.24 \\
COD & 9.5 & $\mathrm{mg} / \mathrm{L}$ & 82.60 & 0.11 & 9.18 \\
TP & 0.03 & $\mathrm{mg} / \mathrm{L}$ & 92.75 & 0.13 & 11.97 \\
TN & 0.2 & $\mathrm{mg} / \mathrm{L}$ & 94.80 & 0.13 & 12.23 \\
Sulfida & 0.013 & $\mathrm{mg} / \mathrm{L}$ & 83.37 & 0.13 & 10.46 \\
Klorophyl a & 5.2 & $\mathrm{mg} / \mathrm{L}$ & 82.84 & 0.11 & 9.2 \\
\hline & & & TOTAL : & 1.00 & 89.34 \\
& & & Indek kualitas air danau $=$ & 89.34 \\
& & & Status kualitas air danau $=$ & Baik \\
\hline
\end{tabular}


Berdasarkan Tabel 4, diperoleh status indeks kualitas air Danau Maninjau sebesar 89,34 dengan kriteria baik. WQI yang diujicobakan pada data kualitas air danau Rawapening di lokasi inlet, ditunjukkan pada Tabel 5. Nilai indeks kualitas air Danau Rawapening di lokasi inlet adalah s ebesar 79,72.

Tabel 5: Perhitungan indeks kualitas air Danau Rawapening di lokasi inlet

\begin{tabular}{|c|c|c|c|c|c|}
\hline Parameter & $\begin{array}{c}\text { Hasil } \\
\text { Pengujian }\end{array}$ & Satuan & $\begin{array}{c}\text { Nilai } \\
\text { Sub-indek }\end{array}$ & $\begin{array}{c}\text { Faktor } \\
\text { Pembobot }\end{array}$ & Sub Total \\
\hline $\mathrm{pH}$ & 7.0 & --- & 102.23 & 0.14 & 14.29 \\
\hline $\mathrm{TSS}$ & 9 & $\mathrm{mg} / \mathrm{L}$ & 98.65 & 0.11 & 10.96 \\
\hline $\mathrm{DO}$ & 4.9 & $\mathrm{mg} / \mathrm{L}$ & 68.17 & 0.14 & 9.77 \\
\hline $\mathrm{COD}$ & 23 & $\mathrm{mg} / \mathrm{L}$ & 73.46 & 0.11 & 8.16 \\
\hline $\mathrm{TP}$ & 0.01 & $\mathrm{mg} / \mathrm{L}$ & 96.90 & 0.13 & 12.5 \\
\hline TN & 0.92 & $\mathrm{mg} / \mathrm{L}$ & 78.34 & 0.13 & 10.11 \\
\hline Sulfida & 0.014 & $\mathrm{mg} / \mathrm{L}$ & 83.16 & 0.13 & 10.43 \\
\hline Klorophyl a & 35 & $\mathrm{mg} / \mathrm{L}$ & 31.38 & 0.11 & 3.49 \\
& & & \multicolumn{3}{c|}{$\begin{array}{c}\text { TOTAL }: \\
\text { Indek kualitas air danau }=\end{array}$} \\
& & & Status kualitas air danau $=$ & 79.72 \\
& & &
\end{tabular}

Selanjutya rumusan Indeks Kualiats Air danau dengan WQI calculator ini diujicobakan pula menggunakan data persyaratan kualitas air sesuai PP 82 klas II tahun 2001 (Tabel 6).

Tabel 6: Perhitungan indeks kualitas air sesuai KMA PP 82 tahun 2001 kelas II

\begin{tabular}{|c|c|c|c|c|c|}
\hline Parameter & $\begin{array}{c}\text { Kada } \\
\text { yang di } \\
\text { persyaratkan } \\
\text { pada PP 82 / } \\
\mathbf{2 0 0 1}\end{array}$ & Satuan & $\begin{array}{c}\text { Nilai } \\
\text { Sub-indek }\end{array}$ & $\begin{array}{c}\text { Faktor } \\
\text { Pembobot }\end{array}$ & Sub Total \\
\hline $\mathrm{pH}$ & 7.0 & --- & 102.23 & 0.14 & 14.29 \\
\hline $\mathrm{TSS}$ & 50 & $\mathrm{mg} / \mathrm{L}$ & 92.37 & 0.11 & 10.26 \\
\hline DO & 4 & $\mathrm{mg} / \mathrm{L}$ & 56.65 & 0.14 & 8.12 \\
\hline COD & 25 & $\mathrm{mg} / \mathrm{L}$ & 73.05 & 0.11 & 8.12 \\
\hline TP & 0.2 & $\mathrm{mg} / \mathrm{L}$ & 77.90 & 0.13 & 10.05 \\
\hline TN & tidak di & $\mathrm{mg} / \mathrm{L}$ & & & 11.88 \\
\hline Sulfida & 0.002 & $\mathrm{mg} / \mathrm{L}$ & 94.67 & 0.13 & \\
\hline Klorophyl a & tidak di & $\mathrm{mg} / \mathrm{L}$ & & & \\
\hline
\end{tabular}

TOTAL :

1.00

62,70

Indek kualitas air danau $=$

82,51

Status kualitas air danau $=$

Baik 
Berdasarkan perbandingan indek kualitas air Danau Maninjau dan Danau Rawapening dengan nilai indeks yang diperoleh dari perhitungan menggunakan nilai KMA kelas II PP No. 82/2001, maka dapat dilihat bahwa kedua status kualitas air danau memiliki nilai kategori yang sama yaitu baik.

\section{KESIMPULAN}

Para ilmuwan, pemerhati, praktisi dan pakar yang berpartisipasi dalam pengisian kuesioner indeks kualitas air danau mempertimbangkan delapan parameter yang meliputi $\mathrm{pH}, \mathrm{DO}$, TSS, COD, TP, TN, Sulfida dan klorofil-a sebagai prioritas parameter yang harus dipantau. Dalam rangka transformasi delapan parameter kualitas air danau tersebut menjadi nilai tunggal, maka perlu dilakukan perhitungan indeks kualitas air danau Water Quality Index (WQI).

WQI digunakan dengan cara, memasukkan kadar parameter hasil pengujian kualitas air danau Maninjau dan danau Rawapening sesuai model matematika yang diperoleh berdasarkan persepsi para pakar dan mengkalikannya dengan pembobotan yang ditetapkan. Berdasarkan perhitungan indeks kualitas air danau Maninjau terhadap 8 parameter, diperoleh nilai indeks 89,34 sedangkan untuk danau Rawapening didapatkan nilai indeks 79,72. Jika kedua hasil indeks tersebut dibandingkan dengan nilai indeks yang diperoleh dari perhitungan menggunakan nilai KMA kelas II PP No.82/ 2001, maka dapat dilihat bahwa kedua status kualitas air danau memiliki nilai kategori yang sama yaitu baik. Hal ini mengacu pada klasifikasi berdasarkan rentang National Sanitation Foundation - Water Quality Index (NSF - WQI), pada kategori baik yaitu $51-70$.

\section{UCAPAN TERIMAKASIH}

Penghargaan yang tulus disertakan ucapan terima kasih disampaikan kepada para petugas pengambil contoh uji dan analis laboratorium Pusat Penelitian dan Pengembangan Kualitas dan Laboratorium Lingkungan - Badan Penelitian, Pengembangan dan Inovasi, Kementerian Lingkungan Hidup dan Kehutanan yang telah membantu kelancaran sehingga tercapainya karya tulis ilmiah ini.

\section{DAFTAR PUSTAKA}

1. Kannel, Prakash Raj, et al. 2007. Application of Water Quality Indices and Dissolved Oxygen as Indicators for River Water Classification and Urban Impact Assessment . Journal of Environmental Monitoring and Assessment, 132:93-110;

2. Prosiding Seminar Nasional Limnologi VI Tahun 2012, Mitigasi Danau Eutrofik Studi Kasus Danau Rawapening.

3. Zhou, Feng, et al. 2003.Application of Multivariate Statistical methods to Water Quality Assessment of the Watercourses in Northwestern New Territories, HongKong. Enviromental Monitoring and Assessment, 119:201-231 
4. Diersing, Nancy (2009). "Water Quality: Frequently Asked Questions" Florida Brooks National Marine Sanctuary, Key West, FL.

5. Johnson, D.L., S.H. Ambrose, T.J. B a s s e t t, M.L. B ow en, D.E. Crummey, J.S. Isaacson, D.N. Johnson, P. Lamb, M. Saul, and A.E. Winter-Nelson (1997). "Meanings of environmental terms." Journal of Environmental Quality. 26: 581-589.

6. Moss, B.; Johnes,P.; Philips,G. 1996. The Monitoring Of Ecology Quality And The Classification of Standing Waters In Temperate Regions; A review And Proposal Based On A worked Scheme For British Waters Biological Review 71(2):, 301-339. Cambridge Philosophical Society

7. William, P.; Whitfield,M; Biggs,J.; Bray,S.; Fox, G.; Nicolet,P. and Sear,D. 2003. Comparative biodiversity of river, stream, ditches and ponds in an agricultural landscape in southern England. Biological Conservation 115; 329-341.

8. Downing J.A., Praire Y.T.,Cole J.J., Duarte C.M.,Tranvick L.J., Kortelainen P., Melack J.M., Middleburg J.J., 2006. The global abundance and size distribution of lake,ponds and impoundments. Limnologi.
9. The Economic and Environment Impact of Phosphorus Removal from Wastewater in the European Community, 1993

10. Janina Zbierska, et all; Changes In The Tropic Status of Lake Niepruszewskie (Poland), Journal of Ecological Engineering ; Volume 16, Issue 4, Oct. 2015, pages 65-73; 2015

11. Development of Water Quality Index Model For Lakes and Reservoirs, The International Society of Paddy and Water Environment Engineering and springer Japan, 2014

12. A. A. Miranda, Y. A. Le Borgne, and G. Bontempi. New Routes from Minimal Approximation Error to Principal Components, Volume 27, Number 3/June, 2008, Neural Processing Letters, Springer

13. Johnson, Richard A \& Wichern, Dean W. Applied Multivariate Statistical Analysis (New Jersey: Prentice-Hall International Inc,1998). ISBN 0-13-080084-8.

14. Akbar A, Ullah MA ; Nonparametric Regression Estimation for Nonlinear Systems: A Case Study of Sigmoidal Growths ; Pakistan Journal of Social Sciences (PJSS); vol. 31, No. 2 (December 2011), pp. 423-432

15. By: Alexakis, Dimitris; Tsihrintzis, Vassilios; Tsakiris, George; Gikas, Georgios. Water Resources Management. Mar 2016, Vol. 30 Issue 5, p1621-1633. 13p. DOI: 10.1007/s11269-016-1240-y. 
Database: Environment Completenearer that of the WFD-ECOFRAME approach when compared to the CCME-WQI. [ABSTRACT FROM )AUTHOR]

16. Water Quality Criteria for Nutrients and Algae, Overview Report, Prepared pursuant to section 2(e) of the Environment Act, 1981 http://www.env.gov.bc.ca/wat/wq/ BCguidelines/nutrients/nutrients.html

17. http://eng.me.go.kr/eng/web/index.do? menuId=123 (Ministry of Environment Korea)

18. http://www.greatswamp.org/10Towns Docs/wqstd602. pdf,Waterquality standard for the great swamp watershed, June 2002, New jersey.

19. Arikunto, Suharsimi. 2006.

Prosedur Penelitian Suatu Pendekatan Praktik. Jakarta : Rineka Cipta.

20. Suitability of Water Quality Indices for Application in Lakes in the Mediterranean, Authors: Alexakis, Dimitris'dial@survey.ntua.gr; Tsihrintzis, Vassilios ${ }^{1}$ Tsakiris,George $^{1}$ Gikas, Georgios'2; Water Resources Management. Mar2016, Vol. 30 Issue 5, p1621-1633. 13p.

21. Herawati, V.E. 2008. Analisis Kesesuaian Perairan Segara Anakan Kabupaten Cilacap Sebagai Lahan Budidaya Kerang Totok (Polymesoda erosa) Ditinjau Dari Aspek Produktifitas Primer Menggunakan Penginderaan $\mathrm{J}$ a $\mathrm{u} \mathrm{h}$. $\mathrm{T}$ e s i s. Universitas Diponegoro. Semarang.

22. http://bcn.boulder.co.us/basin/ watershed/wqi_nsf.html, diunduh tgl 9 November 2016 , jam 14.26
23. Naskah Seminar Tugas Akhir, Kajian Status Kualitas Air di Sungai Gajahwong dengan Berbagai Indeks Kualitas Air, Muslimin , Jurusan Teknik Sipil Dan Lingkungan Fakultas Teknik Universitas Gadjah Mada Yogyakarta, 2011

24. Oviantari dalam " Analisis Indeks Kualitas air pada mata air Tlebusan Baluan, Pancoran Camplung, dan Pancoran Padukuhan di Banjarcau, Tabanan , “ejournal.undiksha.ac.id/index.php/ semnasmipa/article/.../2229

25. Vianisa Anggraeni dkk, dalam " Studi Penentuan Kualitas Air Sungai Babon dengan metode NSF Indeks Kualitas Air 